\title{
Safety and efficacy of aripiprazole for the treatment of pediatric Tourette syndrome and other chronic tic disorders
}

This article was published in the following Dove Press journal:

Pediatric Health, Medicine and Therapeutics

27 June 2016

Number of times this article has been viewed

\author{
Joanna H Cox' \\ Stefano Seri ${ }^{2,3}$ \\ Andrea E Cavanna ${ }^{2,4,5}$ \\ 'Heart of England NHS Foundation \\ Trust, ${ }^{2}$ School of Life and Health \\ Sciences, Aston Brain Centre, \\ Aston University, ${ }^{3}$ Children's \\ Epilepsy Surgery Programme, The \\ Birmingham Children's Hospital \\ NHS Foundation Trust, ${ }^{4}$ Department \\ of Neuropsychiatry, Birmingham \\ and Solihull Mental Health NHS \\ Foundation Trust, Birmingham, ${ }^{5}$ Sobell \\ Department of Motor Neuroscience \\ and Movement Disorders, Institute of \\ Neurology and UCL, London, UK
}

Correspondence: Andrea E Cavanna Department of Neuropsychiatry, The Barberry National Centre for Mental Health, 25 Vincent Drive, Birmingham BI5 2FG, UK

Tel +44 I2I 30I2 3I7

Email a.e.cavanna@bham.ac.uk

\begin{abstract}
Tourette syndrome is a childhood-onset chronic tic disorder characterized by multiple motor and vocal tics and often accompanied by specific behavioral symptoms ranging from obsessionality to impulsivity. A considerable proportion of patients report significant impairment in health-related quality of life caused by the severity of their tics and behavioral symptoms and require medical intervention. The most commonly used medications are antidopaminergic agents, which have been consistently shown to be effective for tic control, but are also associated with poor tolerability because of their adverse effects. The newer antipsychotic medication aripiprazole is characterized by a unique mechanism of action (D2 partial agonism), and over the last decade has increasingly been used for the treatment of tics. We conducted a systematic literature review to assess the available evidence on the efficacy and safety of aripiprazole in pediatric patients with Tourette syndrome and other chronic tic disorders (age range: 4-18 years). Our search identified two randomized controlled trials (involving 60 and 61 participants) and ten open-label studies (involving between six and 81 participants). The majority of these studies used two validated clinician-rated instruments (Yale Global Tic Severity Scale and Clinical Global Impression scale) as primary outcome measures. The combined results from randomized controlled trials and open-label studies showed that aripiprazole is an effective, safe, and well-tolerated medication for the treatment of tics. Aripiprazole-related adverse effects (nausea, sedation, and weight gain) were less frequent compared to other antidopaminergic medications used for tic management and, when present, were mostly transient and mild. The reviewed studies were conducted on small samples and had relatively short follow-up periods, thus highlighting a need for further trials to assess the long-term use of aripiprazole in pediatric patients with Tourette syndrome and other chronic tic disorders with measurement of its efficacy using both clinician-rated and self-report scales.
\end{abstract}

Keywords: Tourette syndrome, tics, aripiprazole, efficacy, tolerability

\section{Background}

Tourette syndrome (TS) is a chronic tic disorder characterized by the presence of both motor and vocal tics: repetitive movements and noises expressed as a result of specific sensory experiences or premonitory urges. ${ }^{1}$ The prevalence of TS worldwide is estimated to be up to $1 \%$ in school-age children and a male:female prevalence ratio of 3-4:1 has been consistently documented. ${ }^{2}$ The average age of tic onset is reported to be 6-7 years and peak severity is usually reached by early teenage years. ${ }^{3-5}$ The other chronic tic disorders (chronic motor or vocal tic disorder) follow a similar neurodevelopmental trajectory, often with less severe symptoms than TS. In a significant 
proportion of patients, tics improve and, in some cases, disappear by adulthood, ${ }^{6,7}$ although the characteristic urges are reported by the vast majority of adult patients with persisting symptoms. ${ }^{8,9}$ TS is associated with neuropsychiatric comorbidities in $\sim 90 \%$ of patients. ${ }^{2,3,10}$ The most common comorbid conditions are obsessive-compulsive disorder ${ }^{11}$ and attention-deficit and hyperactivity disorder, ${ }^{12}$ which have been shown to significantly affect health-related quality of life, ${ }^{13}$ as well as impulse control disorders. ${ }^{14,15}$

Although the exact neurobiological mechanisms underlying TS and other chronic tic disorders remain unclear, there is converging evidence on the role of disruption to neurotransmission within the cortico-striato-thalamo-cortical pathways. ${ }^{6,16}$ The pathophysiological processes are thought to involve dysregulation of dopaminergic neurotransmission; however, both histaminergic ${ }^{17,18}$ and noradrenergic ${ }^{19,20}$ pathways have also been proposed to be involved. These neurochemical changes have consistently been associated with genetic susceptibility, although no single causative gene defect has been identified. ${ }^{21,22}$ It is possible that the genetic heterogeneity which characterizes TS reflects the heterogeneity of the clinical phenotypes.

Treatment approaches to TS and other chronic tic disorders show a considerable variability, depending on the severity and complexity of the clinical picture. In some cases, simple reassurance and psychoeducation are the only required interventions. ${ }^{23}$ In more severe cases, pharmacological therapy or behavioral interventions, such as habit reversal therapy, are often indicated. ${ }^{24,25}$ Furthermore, over the last 15 years, there have been several reports of patients with severe and treatment-refractory TS who underwent the neurosurgical procedure of deep brain stimulation in order to control their symptoms. ${ }^{26}$

The pharmacological treatment of TS and other chronic tic disorders encompasses different drug classes and recommendations are often based on the findings of open-label studies. ${ }^{27}$ The most commonly used medications are antidopaminergic agents (neuroleptics or atypical antipsychotics), ${ }^{28,29}$ which are associated with known adverse effects. ${ }^{30}$ Other medications used include alpha-2 adrenoreceptor agonists, such as clonidine and guanfacine. ${ }^{31}$ Serotonergic medications are helpful for obsessive-compulsive disorder symptoms, whereas central nervous system stimulants, such as methylphenidate, can be used for the treatment of comorbid attention-deficit and hyperactivity disorder.

Over the last decade, aripiprazole has increasingly been used for the treatment of children and adolescents with TS and other chronic tic disorders. Aripiprazole is an atypi- cal antipsychotic agent licensed for use in the treatment of schizophrenia and mania in bipolar affective disorder. ${ }^{32,33}$ The mechanism of action of aripiprazole appears to be pharmacologically distinct from that of other atypical antipsychotics. This medication was initially reported to be a high-affinity D2 dopamine receptor partial agonist, ${ }^{34,35}$ although more recent pharmacological profiling studies have indicated a more complex mechanism of action. ${ }^{36}$ Aripiprazole appears to display functionally significant interactions at a large number of amine G-protein coupled receptors, including D2, D3, and D4 dopamine receptors, as well as at least six subtypes of serotonin receptors. The mode of action of aripiprazole at the level of the different receptors appears to be variable, with studies showing evidence for action as a full agonist, partial agonist, inverse agonist, and antagonist, depending on the receptor involved. The most frequently demonstrated mechanism is partial agonism at the level of dopaminergic and serotonergic receptors. In consideration of the rapidly expanding literature on the usefulness of aripiprazole in children and adolescents with TS, we set out to conduct a systematic review focusing on both safety and efficacy and encompassing randomized controlled trials and open-label studies in pediatric patients with TS and other chronic tic disorders.

\section{Methods}

This article reviews the available evidence on the efficacy and safety of aripiprazole in pediatric patients with TS and other chronic tic disorders. We conducted a systematic literature review on the PubMed database according to the methodological standards set out in the PRISMA (Preferred Reporting Items for Systematic Reviews and Meta-Analyses) guidelines. ${ }^{37}$ Exclusion criteria covered studies published in languages other than English, studies involving adult populations only, studies assessing the use of aripiprazole in conditions other than chronic tic disorders, and any molecular or animal studies. Case reports were individually assessed for relevance to our review. Studies in which the full data were not available (eg, conference abstracts) and other types of publications (eg, editorials, commentaries, letters to the editor) were excluded. Finally, reference lists from both retrieved studies and recent review articles were manually scanned to ensure that any additional relevant studies were not missed.

Our search identified two randomized controlled trials and ten open-label studies. The majority of these studies used Yale Global Tic Severity Scale (YGTSS) scores as their primary outcome measure for drug efficacy on tic control. The YGTSS is a clinician-rated scale of tic severity, which includes a number of different subscores. ${ }^{38,39}$ Patients are 
scored on the severity of their motor and phonic tics separately, and these scores can be combined to produce a total tic severity score out of 50. A higher score denotes a higher severity of tics. The total tic severity score, which takes into account the number, frequency, intensity, complexity, and interference of tics, is subsequently combined with a $0-50$ impairment score, measuring the effect of tics on a person's overall daily functioning. The sum of the tic severity and impairment scores yields the global YGTSS score, with a maximum of 100 points. A few relevant studies also used the Clinical Global Impression (CGI) scale, a clinician-rated measure which assesses change in global daily functioning on a 7-point Likert-type scale. ${ }^{40}$ The CGI scale is not uniquely used in patients with tic disorders as it is frequently used across different neuropsychiatric and psychiatric conditions. ${ }^{41}$ This instrument includes two subscores assessing the severity of symptoms and clinical improvement, respectively.

\section{Randomized controlled trials}

To date, two randomized controlled trials assessing the use of aripiprazole in young patients with TS and other chronic tic disorders have been published. The first trial was carried out between 2008 and 2010 by a research group based in the South Korea. ${ }^{42}$ Their study involved 61 patients (age range: $6-18$ years) recruited across six centers. The authors assessed the efficacy of aripiprazole by measuring change in the total YGTSS scores and CGI-Improvement scores from baseline in 32 patients treated with aripiprazole compared to 29 patients who received placebo. The study took place over a 10-week period with YGTSS scores, CGI scores, and tolerability being assessed on a fortnightly basis. Aripiprazole was started at a dose of $2 \mathrm{mg}$ /day with the possibility of gradually increasing it to $5,10,15$, or $20 \mathrm{mg}$ /day, according to tolerability and tic severity. The mean dose of aripiprazole across the study sample was $11 \mathrm{mg} /$ day. At the end of the study period, mean YGTSS scores were decreased by 15.0 points in the aripiprazole group and 9.6 points in the placebo group. This difference was statistically significant. Interestingly, the mean decrease in phonic tic severity was significantly larger in the aripiprazole group when compared to placebo. No difference was found in motor tic severity. Furthermore, the magnitude of the TS CGI severity score was significantly lower in the aripiprazole group compared to the placebo group. No patients in this study discontinued their treatment due to adverse effects; however, $75 \%$ of patients in the aripiprazole group reported adverse effects. Notably, over $71 \%$ of patients in the placebo group also reported adverse effects. The most frequently reported effects included nausea, headache, sedation, somnolence, and nasopharyngitis. Both body weight and body mass index were significantly increased following aripiprazole treatment; however, no clinically significant changes were found on glucose and cholesterol measurement. The authors concluded that aripiprazole is an efficacious treatment for the management of TS in children and adolescents that is generally well tolerated and safe in the short term.

In the second randomized controlled trial, which was published in 2013, aripiprazole was compared to risperidone in the treatment of children and adolescents with tic disorders. ${ }^{43}$ The study involved 60 patients between the ages of 6 and 18 years recruited from child psychiatry clinics affiliated with the Shiraz University of Medical Sciences in Iran. The study participants were randomly allocated to receiving either aripiprazole $(n=31)$ or risperidone $(n=29)$, and their YGTSS scores were assessed at baseline, week 4, and week 8 . The initial dose of aripiprazole was $1.25 \mathrm{mg} /$ day to be gradually increased up to 10 or $15 \mathrm{mg}$ /day, depending on the child's weight. The mean dose of aripiprazole used was 3.22 and $4.0 \mathrm{mg} /$ day in the first and second month of the trial, respectively. At baseline, the mean tic severity scores did not differ between the two groups. At the end of the study, both aripiprazole and risperidone were found to significantly decrease the YGTSS total tic severity score, as well as the motor and phonic tic subscores. The authors found no significant differences in the decrease in scores between the aripiprazole and the risperidone groups. The most common adverse effects reported in the aripiprazole group were drowsiness (26\%), increased appetite (26\%), and decreased appetite $(13 \%)$. One patient dropped out of the study due to severe sedation. The authors concluded that risperidone and aripiprazole are both effective in managing tics in children and adolescents with TS. They suggested that further studies assessing tolerability and efficacy of long-term use of these medications should be undertaken.

\section{Open-label studies}

Our literature search identified ten open-label trials of aripiprazole in young patients with chronic tic disorders, which are summarized in Table 1.

The first pilot study assessing the efficacy of aripiprazole in a pediatric population was published by a Korean group in $2006 .{ }^{44}$ The authors treated six patients aged between 7 and 17 years with aripiprazole at a mean dose of $10.9 \mathrm{mg}$ and compared their YGTSS total severity scores at baseline with those after 8 weeks of treatment. In this study population, there was a $40.1 \%$ decrease in YGTSS scores at 8 weeks 
Table I Summary of open-label studies on the use of aripiprazole in children and adolescents with tic disorders

\begin{tabular}{|c|c|c|c|c|c|c|c|}
\hline Study & Location & Patients, $\mathbf{n}$ & $\begin{array}{l}\text { Protocol length, } \\
\text { mean dose }\end{array}$ & $\begin{array}{l}\text { YGTSS (decrease } \\
\text { in total tic score), } \\
\%\end{array}$ & CGI & Adverse effects & $\begin{array}{l}\text { Dropout due } \\
\text { to adverse } \\
\text { effects, } \%\end{array}$ \\
\hline Yoo et al ${ }^{44}$ & South Korea & 6 & 8 weeks, $10.9 \mathrm{mg} /$ day & 40.1 & - & $\begin{array}{l}\text { Vomiting, sedation, } \\
\text { weight gain }\end{array}$ & 16.7 \\
\hline Yoo et $\mathrm{al}^{45}$ & South Korea & 24 & 8 weeks, $9.8 \mathrm{mg} /$ day & 52.8 & $\begin{array}{l}79.2 \% \text { much/very } \\
\text { much improved }\end{array}$ & $\begin{array}{l}\text { Sedation, nausea, } \\
\text { headache }\end{array}$ & 25.0 \\
\hline Seo et $\mathrm{al}^{48}$ & South Korea & 15 & 12 weeks, $8.2 \mathrm{mg} /$ day & 55.7 & - & Nausea, sedation & 6.7 \\
\hline Budman et al ${ }^{49}$ & USA & 37 & 12 weeks, $11.7 \mathrm{mg} / \mathrm{day}$ & - & $\begin{array}{l}38.6 \% \text { decrease in } \\
\text { CGI severity score }\end{array}$ & $\begin{array}{l}\text { Headaches, dizziness, } \\
\text { nausea }\end{array}$ & 22.0 \\
\hline Lyon et al ${ }^{50}$ & USA & 11 & 10 weeks, $4.5 \mathrm{mg} /$ day & 40.8 & $\begin{array}{l}91.0 \% \text { much/very } \\
\text { much improved, } \\
28.5 \% \text { decrease in } \\
\text { CGl severity score }\end{array}$ & $\begin{array}{l}\text { Increased appetite, } \\
\text { extrapyramidal, } \\
\text { akathisia }\end{array}$ & 9.1 \\
\hline Murphy et $\mathrm{al}^{51}$ & USA & 16 & 6 weeks, $3.3 \mathrm{mg} /$ day & 54.1 & - & $\begin{array}{l}\text { Restlessness, } \\
\text { irritability, nausea }\end{array}$ & 0.0 \\
\hline Cui et $a^{52}$ & $\begin{array}{l}\text { People's } \\
\text { Republic of } \\
\text { China }\end{array}$ & 72 & 8 weeks, $8.2 \mathrm{mg} /$ day & 50.3 & $\begin{array}{l}53.9 \% \text { decrease in } \\
\text { CGl severity score }\end{array}$ & Nausea, sedation & 2.8 \\
\hline Yoo et al ${ }^{46}$ & South Korea & 48 & 8 weeks, $10.6 \mathrm{mg} /$ day & 54.3 & $\begin{array}{l}71.0 \% \text { much/very } \\
\text { much improved }\end{array}$ & $\begin{array}{l}\text { Sedation, nausea, } \\
\text { extrapyramidal }\end{array}$ & 16.1 \\
\hline Masi et $\mathrm{al}^{53}$ & Italy & 28 & 12 weeks, $10.0 \mathrm{mg} / \mathrm{day}$ & 44.7 & - & $\begin{array}{l}\text { Sedation, agitation, } \\
\text { nausea }\end{array}$ & 0.0 \\
\hline Ho et $a^{147}$ & Taiwan & 81 & 14 weeks, $2.8 \mathrm{mg} /$ day & $7.0^{*}$ & - & $\begin{array}{l}\text { Sedation, increased } \\
\text { appetite, decreased } \\
\text { appetite }\end{array}$ & II.I \\
\hline
\end{tabular}

Note: *Total YGTSS scores (including overall impairment). “-” indicates the data is not available.

Abbreviations: CGI, Clinical Global Impression; YGTSS, Yale Global Tic Severity Scale.

compared to baseline, with a decrease in the mean scores from 27.6 to 16.6 . One patient withdrew from the study due to vomiting, but aripiprazole was otherwise well tolerated.

This research group subsequently published two further studies on the use of aripiprazole in children and adolescents with tic disorders. The first of these two studies was a larger open-label trial involving 24 patients with tic disorders aged 7-18 years. ${ }^{45}$ The mean dose of aripiprazole administered to participants was $9.8 \mathrm{mg}$. There was an overall $52.8 \%$ reduction in YGTSS scores at 8 weeks, and $79.2 \%$ of the cohort was rated as having tic symptoms either much improved or very much improved on the CGI scale. In this study, six patients $(25 \%)$ prematurely discontinued aripiprazole due to adverse effects. The second study compared aripiprazole to haloperidol in the treatment of TS over an 8-week period. ${ }^{46}$ This study involved 48 patients aged 6-15 years, 31 of whom were prescribed aripiprazole at a mean dose of $10.6 \mathrm{mg}$. At 8 weeks, there was a higher percentage decrease in total YGTSS scores in the haloperidol group compared to the aripiprazole group (63.4\% vs $54.3 \%$ ); however, the dropout rate due to adverse effects was higher in the haloperidol group. Interestingly, the proportion of patients deemed to be much improved or very much improved on the CGI scale was higher in the aripiprazole group (71.0\%) compared to the haloperidol group (58.8\%).

The largest open-label study to date was published in 2013 by a research group based in Taiwan. ${ }^{47}$ These authors treated 81 patients with TS aged between 4 and 18 years with aripiprazole at a mean dose of $2.84 \mathrm{mg} /$ day and recorded their YGTSS following 14 weeks of therapy. Nine patients withdrew due to adverse effects, 15 withdrew due to being symptom free for 2 weeks, and two withdrew as they experienced no significant beneficial effect. There was a mean reduction of $51 \%$ in motor tic scores, $67.1 \%$ in phonic tic scores, and $70 \%$ in total YGTSS scores. The authors concluded that aripiprazole is a safe and generally well tolerated, effective medication for the treatment of tics in children. One of the main limitations of this study was the large percentage $(65.4 \%)$ of patients with a diagnosis of transient tic disorder. This reduces the generalizability of the results to the wider patient with TS population, as the positive results may have been biased by the large number of patients who had transient and mild symptoms.

The combined results of the remaining six open-label studies ${ }^{4-53}$ confirmed the efficacy of aripiprazole in reducing both motor and vocal tic severity (Table 1). These studies 
were conducted on clinical cohorts of between eleven ${ }^{50}$ and $72^{52}$ children and adolescents with tic disorders. Over study periods of 6-14 weeks, aripiprazole resulted in an overall reduction in tic severity in all cohorts for which data have been published. The mean dose of aripiprazole used in these open-label studies varied considerably from $2.8 \mathrm{mg} /$ day in the study by Ho et $\mathrm{al}^{47}$ to $11.7 \mathrm{mg} /$ day in the study by Budman et $\mathrm{al},{ }^{49}$ possibly accounting for some of the variability in effect size across studies. A few studies reported evidence for a larger improvement in vocal tics following administration of aripiprazole..$^{47,51,53}$ Interestingly, this observation is in line with the findings of the randomized controlled trial by Yoo et al. ${ }^{42}$ Moreover, one study assessed aripiprazole in the setting of patients with comorbid TS and attention-deficit and hyperactivity disorder, and presented encouraging results for the role of this medication in managing comorbidities in addition to improving tics. ${ }^{53}$

The full picture emerging from the combined analysis of all the reviewed open-label studies (ten studies; 338 patients) indicates a decrease in YGTSS total tic severity scores of $49.1 \%$ (combined data from eight studies) and a dropout due to adverse effects of $11.0 \%$ (combined data from ten studies).

\section{Safety and tolerability issues}

Aripiprazole appears to be a safe and generally well tolerated pharmacological option for young patients with TS and other chronic tic disorders. In the published randomized controlled trials and open-label studies, withdrawal rates varied between $0 \%$ and $25 \%$. The most frequently cited adverse effects included nausea, vomiting, fatigue, sedation, and weight gain, similar to what has been reported in the wider scientific literature on its use in child and adolescent psychiatry. ${ }^{54}$ The majority of adverse effects appear to be transient and settle within the first few weeks of treatment, although in a few cases increased appetite and weight gain can cause long-term problems. Not all the reviewed studies quantified weight gain in their patient cohorts, and there is wide variability in the reported findings. Some studies reported prevalence figures of significant weight gain as high as $87 \%,{ }^{49}$ whereas other studies found no significant difference in body mass index after comparing pre- and post-aripiprazole body weight. ${ }^{48}$ Moreover, although weight gain was frequently reported as a possible adverse effect of aripiprazole, it was not clinically significant in the majority of studies. Of note, the longest observational period for the reviewed studies was 14 weeks, thus suggesting that more long-term studies are required to assess the true impact of aripiprazole on body weight. Another adverse effect associated with atypical antipsychot- ics is QTc prolongation on electrocardiogram. This is often an asymptomatic complication of drug treatment but can predispose to dangerous cardiac arrhythmias. The available evidence, including findings from studies conducted in young patients with TS, ${ }^{30}$ indicates that aripiprazole is characterized by an overall safer cardiological profile than other antidopaminergic agents. ${ }^{55,56} \mathrm{In}$ the study by Cui et a ${ }^{52}$ on 72 Chinese children with tic disorders, 13 were found to have a longer QTc on electrocardiogram after aripiprazole treatment when compared to baseline; however, the QTc alteration did not meet age- and sex-related criteria to be defined as prolonged.

\section{Patient-focused perspectives}

Patient-focused perspectives are important components of the clinical assessment and outcome of patients with conditions characterized by both physical and psychological symptoms. TS is a neuropsychiatric disorder with motor and behavioral aspects, which can have significant effects on patients' health-related quality of life $^{57}$ from an early age. ${ }^{58}$ It is therefore important to consider the effects of pharmacological treatments on subjective aspects quality of life, in addition to tic frequency and severity. Both the YGTSS and CGI scales used in the reviewed studies of aripiprazole in young patients with tic disorder are clinician-rated instruments. Although use of these instruments may provide more consistency among assessments, there is the possibility that opinions and feelings of the patients and their caregivers are overlooked. Medications, particularly antipsychotics, are associated with a range of adverse effects of different severity, which can have a negative impact on overall quality of life. In a recent qualitative study, young patients with TS and their parents were surveyed and interviewed to explore their perceptions of treatment. ${ }^{59}$ There was a strong perception among participants that health professionals had limited knowledge of the multifaceted clinical picture of TS and the available treatment options. The general consensus was that pharmacological treatment was beneficial in the management of TS; however, adverse effects were common. Interestingly, this study found that aripiprazole was viewed the most positively, with almost $70 \%$ of participants reporting it as being somewhat or very helpful, and only $25 \%$ reporting moderate or severe adverse effects. These figures were significantly better than those reported for the other seven frequently used medications for tic symptoms.

\section{Conclusion}

Taken together, the available evidence from both randomized controlled trials and open-label studies suggests that 
aripiprazole is an effective, safe, and well-tolerated medication for the treatment of TS and other tic disorders in pediatric populations. These findings are in line with the results of three recently published meta-analyses, which suggested that aripiprazole appears to be a safe and promising therapy for children tic disorders, ${ }^{60,61}$ with similar efficacy to established treatment options, such as the neuroleptics haloperidol and tiapride, and fewer extrapyramidal adverse effects than haloperidol. ${ }^{62}$ Large case series of adult patients with TS provide further support to these observations in terms of both safety ${ }^{63}$ and efficacy. ${ }^{64,65}$ Specifically, pharmacotherapy with aripiprazole has been consistently shown to result in significant reductions in tic severity as measured by the YGTSS. Likewise, the studies that used the CGI scale as an outcome measure found significant improvements in a large proportion of patients. Variable proportions of patients reported adverse effects from aripiprazole, most commonly nausea, sedation, and weight gain. These adverse effects appeared to be primarily transient and mild, and withdrawal rates from trials were low. Adverse effects also appeared to be fewer in frequency and milder in severity when compared to other medications used in the pharmacological treatment of tic symptoms.

In conclusion, the vast majority of studies considered in this review were of relatively low power due to small sample sizes. Of note, only two studies were deemed eligible to be included in a recent meta-analysis on the efficacy and safety of aripiprazole for patients of all ages with a diagnosis of TS, ${ }^{62}$ suggesting that further randomized controlled trials should be undertaken on larger patient cohorts. A multicenter randomized controlled trial on the efficacy and safety of once-weekly oral aripiprazole in children adolescents with TS was registered in 2011 (ClinicalTrials.gov identifier: NCT01418339). Moreover, the patients recruited in the reviewed studies were followed-up for a relatively short period of time (up to 3-4 months) and the fact that most of the studies were performed in Asian countries might have possibly introduced a bias in their results. Further studies are needed to establish whether the beneficial effects and tolerability of aripiprazole persist with time and whether they can lead to symptom freedom. Future research should therefore be targeted at longer-term use of aripiprazole in pediatric patients with TS and other chronic tic disorders with measurement of its efficacy using both clinician-rated and self-report scales. This will help defining the role of aripiprazole in evidence-based practice guidelines on the treatment of children and adolescents with tic disorders. ${ }^{66}$

\section{Disclosure}

SS has received educational grants from Eisai Pharmaceuticals, UCB Pharma, and Beacon Pharmaceuticals Limited; AEC is a member of the Medical Advisory Board of the Tourette Association of America and has received Board Membership fees and research grants from Eisai Pharmaceuticals and lectureship grants from Eisai Pharmaceuticals, UCB Pharma, and Janssen-Cilag. The authors report no other conflicts of interest in this work.

\section{References}

1. Leckman JF, Bloch MH, Scahill L, King RA. Tourette syndrome: the self under siege. J Child Neurol. 2006;21(8):642-649.

2. Cavanna AE, Seri S. Tourette's syndrome. BMJ. 2013;347:f4964.

3. Freeman RD, Fast DK, Burd L, Kerbeshian J, Robertson MM, Sandor P. An international perspective on Tourette syndrome: selected findings from 3,500 individuals in 22 countries. Dev Med Child Neurol. 2000;42(7):436-447.

4. Tamara P. Tourette syndrome and other tic disorders of childhood. Handb Clin Neurol. 2013;112:853-856.

5. Ong MT, Mordekar SR, Seal A. Fifteen minute consultation: tics and Tourette syndrome. Arch Dis Child Educ Pract Ed. 2016;101(2):87-94.

6. Singer HS. Tourette's syndrome: from behaviour to biology. Lancet Neurol. 2005;4(3):149-159.

7. Hassan N, Cavanna AE. The prognosis of Tourette syndrome: implications for clinical practice. Funct Neurol. 2012;27(1):23-27.

8. Crossley E, Cavanna AE. Sensory phenomena: clinical correlates and impact on quality of life in adult patients with Tourette syndrome. Psychiatry Res. 2013;209(3):705-710.

9. Crossley E, Seri S, Stern JS, Robertson MM, Cavanna AE. Premonitory urges for tics in adult patients with Tourette syndrome. Brain Dev. 2014;36(1):45-50.

10. Hirschtritt ME, Lee PC, Pauls DL, et al. Lifetime prevalence, age of risk, and genetic relationships of comorbid psychiatric disorders in Tourette syndrome. JAMA Psychiatry. 2015;72(4):325-333.

11. Lombroso PJ, Scahill L. Tourette syndrome and obsessive-compulsive disorder. Brain Dev. 2008;30(4):231-237.

12. El Malhany N, Gulisano M, Rizzo R, Curatolo P. Tourette syndrome and comorbid ADHD: causes and consequences. Eur J Pediatr. 2015;174(3):279-288.

13. Eddy CM, Cavanna AE, Gulisano M, Calì P, Robertson MM, Rizzo R. The effects of comorbid obsessive-compulsive disorders and attentiondeficit hyperactivity disorder on quality of life in Tourette syndrome. $J$ Neuropsychiatry Clin Neurosci. 2012;24(4):458-462.

14. Frank MC, Piedad J, Rickards H, Cavanna AE. The role of impulse control disorders in Tourette syndrome: an exploratory study. J Neurol Sci. 2011;310(1-2):276-278.

15. Wright A, Rickards H, Cavanna AE. Impulse control disorders in Gilles de la Tourette syndrome. JNeuropsychiatry Clin Neurosci. 2012;24(1):16-27.

16. Serajee FJ, Mahubul Huq AH. Advances in Tourette syndrome: diagnoses and treatment. Pediatr Clin North Am. 2015;62(3):687-701.

17. Cox JH, Seri S, Cavanna AE. Histaminergic modulation in Tourette syndrome. Expert Opin Orphan Drugs. 2016;4(2):205-213.

18. Rapanelli M, Pittenger C. Histamine and histamine receptors in Tourette syndrome and other neuropsychiatric conditions. Neuropharmacology. Epub 2015 Aug 14.

19. Chou IC, Tsai CH, Wan L, Hsu YA, Tsai FJ. Association study between Tourette's syndrome and polymorphisms of noradrenergic genes (ADRA2A, ADRA2C). Psychiatr Genet. 2007;17(6):359.

20. Udvardi PT, Nespoli E, Rizzo F, Hengerer B, Ludolph AG. Nondopaminergic neurotransmission in the pathophysiology of Tourette syndrome. Int Rev Neurobiol. 2013;112:95-130. 
21. Deng H, Gao K, Jankovic J. The genetics of Tourette syndrome. Nat Rev Neurol. 2012(4);8:203-213.

22. Paschou P, Fernandez TV, Sharp F, Heiman GA, Hoekstra PJ. Genetic susceptibility and neurotransmitters in Tourette syndrome. Int Rev Neurobiol. 2013;112:155-177.

23. Robertson MM. A personal 35 year perspective on Gilles de la Tourette syndrome: assessment, investigations, and management. Lancet Psychiatry. 2015;2(1):88-104.

24. Piacentini J, Woods DW, Scahill L, et al. Behavior therapy for children with Tourette disorder: a randomized controlled trial. JAMA. 2010;303(19):1929-1937.

25. Dutta N, Cavanna AE. The effectiveness of habit reversal therapy in the treatment of Tourette syndrome and other chronic tic disorders: a systematic review. Funct Neurol. 2013;28(1):7-12.

26. Schrock LE, Mink JW, Woods DW, et al. Tourette Syndrome Association International Deep Brain Stimulation (DBS) Database and Registry Study Group. Tourette syndrome deep brain stimulation: a review and updated recommendations. Mov Disord. 2015;30(4):448-471.

27. Waldon K, Hill S, Termine C, Balottin U, Cavanna AE. Trials of pharmacological interventions for Tourette syndrome: a systematic review. Behav Neurol. 2013;26(4):265-273.

28. Huys D, Hardenacke K, Poppe P, Bartsch C, Baskin B, Kuhn J. Update on the role of antipsychotics in the treatment of Tourette syndrome. Neuropsychiatr Dis Treat. 2012;8:95-104

29. Budman CL. The role of atypical antipsychotics for treatment of Tourette's syndrome: an overview. Drugs. 2014;74(11):1177-1193.

30. Gulisano M, Calì PV, Cavanna AE, Eddy C, Rickards H, Rizzo R. Cardiovascular safety of aripiprazole and pimozide in young patients with Tourette syndrome. Neurol Sci. 2011;32(6):1213-1217.

31. Cavanna AE, Selvini C, Termine C, Balottin U, Eddy CM. Tolerability profile of clonidine in the treatment of adults with Tourette syndrome. Clin Neuropharmacol. 2012;35(6):269-272.

32. Cassano GB, Fagiolini A, Lattanzi L, et al. Aripiprazole in the treatment of schizophrenia: a consensus report produced by schizophrenia experts in Italy. Clin Drug Investig. 2007;27(1):1-13.

33. De Fazio P, Girardi P, Maina G, et al. Aripiprazole in acute mania and long-term treatment of bipolar disorder: a critical review by an Italian working group. Clin Drug Investig. 2010;30(12):827-841.

34. Inoue $T$, Domae M, Yamada K, Furukawa T. Effects of the novel antipsychotic agent 7-(4-[4-(2,3-dichlorophenyl)-1-piperazinyl] butyloxy)-3,4-dihydro -2(1H)-quinolinone (OPC-14597) on prolactin release from the rat anterior pituitary gland. $J$ Pharmacol Exp Ther. 1996;277(1):137-143.

35. Lawler CP, Prioleau C, Lewis MM, et al. Interactions of the novel antipsychotic aripiprazole (OPC-14597) with dopamine and serotonin receptor subtypes. Neuropsychopharmacology. 1999;20(6):612-627.

36. Di Sciascio G, Riva MA. Aripiprazole: from pharmacological profile to clinical use. Neuropsychiatr Dis Treat. 2015;11:2635-2647.

37. Moher D, Liberati A, Tetzlaff J, Altman DG; PRISMA Group. Preferred reporting items for systematic reviews and meta-analyses: the PRISMA statement. Ann Intern Med. 2009;151(4):264-269.

38. Leckman JF, Riddle MA, Hardin MT, et al. The Yale Global Tic Severity Scale: initial testing of a clinician-rated scale of tic severity. J Am Acad Child Adolesc Psychiatry. 1989;28(4):566-573.

39. Storch EA, Murphy TK, Geffken GR, et al. Reliability and validity of the Yale Global Tic Severity Scale. Psychol Assess. 2005;17(4):486-491.

40. Busner J, Targum SD. The clinical global impressions scale: applying a research tool in clinical practice. Psychiatry. 2007;4(7):28-37.

41. Walkup JT, Rosenberg LA, Brown J, Singer HS. The validity of instruments measuring tic severity in Tourette's syndrome. J Am Acad Child Adolesc Psychiatry. 1992;31(3):472-477.

42. Yoo HK, Joung YS, Lee JS, et al. A multicenter, randomized, doubleblind, placebo-controlled study of aripiprazole in children and adolescents with Tourette's disorder. J Clin Psychiatry. 2013;74(8):772-780.
43. Ghanizadeh A, Haghighi A. Aripiprazole versus risperidone for treating children and adolescents with tic disorder: a randomized double blind clinical trial. Child Psychiatry Hum Dev. 2014;45(5):596-603.

44. Yoo HK, Kim JY, Kim CY. A pilot study of aripiprazole in children and adolescents with Tourette's disorder. J Child Adolesc Psychopharmacol. 2006;16(4):505-506.

45. Yoo HK, Choi SH, Park S, Wang HR, Hong JP, Kim CY. An openlabel study of the efficacy and tolerability of aripiprazole for children and adolescents with tic disorders. J Clin Psychiatry. 2007;68(7): 1088-1093.

46. Yoo HK, Lee JS, Paik KW, et al. Open-label study comparing the efficacy and tolerability of aripiprazole and haloperidol in the treatment of pediatric tic disorders. Eur Child Adolesc Psychiatry. 2011;20(3): $127-135$.

47. Ho CS, Chiu NC, Tseng CF, Huang YL. Clinical effectiveness of aripiprazole in short-term treatment of tic disorder in children and adolescents: a naturalistic study. Pediatr Neonatol. 2014;55(1): $48-52$.

48. Seo WS, Sung HM, Sea HS, Bai DS. Aripiprazole treatment of children and adolescents with Tourette disorder or chronic tic disorder. $J$ Child Adolesc Psychopharmacol. 2008;18(2):197-205.

49. Budman C, Coffey BJ, Shechter R, et al. Aripiprazole in children and adolescents with Tourette disorder with and without explosive outbursts. J Child Adolesc Psychopharmacol. 2008;18(5):509-515.

50. Lyon GJ, Samar S, Jummani R, et al. Aripiprazole in children and adolescents with Tourette's disorder: an open-label safety and tolerability study. J Child Adolesc Psychopharmacol. 2009;19(6):623-633.

51. Murphy TK, Mutch PJ, Reid JM, et al. Open label aripiprazole in the treatment of youth with tic disorders. JChild Adolesc Psychopharmacol. 2009;19(4):441-447.

52. Cui YH, Zheng Y, Yang YP, Liu J, Li J. Effectiveness and tolerability of aripiprazole in children and adolescents with Tourette's disorder: a pilot study in China. J Child Adolesc Psychopharmacol. 2010;20(4):291-298.

53. Masi G, Gagliano A, Siracusano R, et al. Aripiprazole in children with Tourette's disorder and co-morbid attention-deficit/hyperactivity disorder: a 12-week, open-label, preliminary study. J Child Adolesc Psychopharmacol. 2012;22(2):120-125.

54. Greenaway M, Elbe D. Focus on aripiprazole: a review of its use in child and adolescent psychiatry. J Can Acad Child Adolesc Psychiatry. 2009;18(3):250-260.

55. Fanoe S, Kristensen D, Fink-Jensen A, et al. Risk of arrhythmia induced by psychotropic medications: a proposal for clinical management. Eur Heart J. 2014;35(20):1306-1315.

56. Jensen KG, Juul K, Fink-Jensen A, Correll CU, Pagsberg AK. Corrected QT changes during antipsychotic treatment of children and adolescents: a systematic review and meta-analysis of clinical trials. JAm Acad Child Adolesc Psychiatry. 2015;54(1):25-36.

57. Cavanna AE, David K, Bandera V, et al. Health-related quality of life in Gilles de la Tourette syndrome: a decade of research. Behav Neurol. 2013;27(1):83-93.

58. Cavanna AE, David K, Robertson MM, Orth M. Predictors during childhood of future health-related quality of life in adults with Gilles de la Tourette syndrome. Eur J Paediatr Neurol. 2012;16(6): 605-612.

59. Cuenca J, Glazebrook C, Kendall T, et al. Perceptions of treatment for tics among young people with Tourette syndrome and their parents: a mixed methods study. BMC Psychiatry. 2015;15:46.

60. Yang CS, Huang H, Zhang LL, Zhu CR, Guo Q. Aripiprazole for the treatment of tic disorders in children: a systematic review and metaanalysis. BMC Psychiatry. 2015;15:179.

61. Liu Y, Ni H, Wang C, Li L, Cheng Z, Weng Z. Effectiveness and tolerability of aripiprazole in children and adolescents with Tourette's disorder: a meta-analysis. $J$ Child Adolesc Psychopharmacol. Epub 2016 Feb 25. 
62. Zheng W, Li XB, Xiang YQ, et al. Aripiprazole for Tourette's syndrome: a systematic review and meta-analysis. Hum Psychopharmacol. 2016;31(1):11-18.

63. Cavanna AE, Selvini C, Termine C, Luoni C, Eddy CM, Rickards H. Tolerability profile of aripiprazole in patients with Tourette syndrome. J Psychopharmacol. 2012;26(6):891-895.

64. Neuner I, Nordt C, Schneider F, Kawohl W. Effectiveness of aripiprazole in the treatment of adult Tourette patients up to 56 months. Hum Psychopharmacol. 2012;27(4):364-369.
65. Wenzel C, Kleimann A, Bokemeyer S, Müller-Vahl KR. Aripiprazole for the treatment of Tourette syndrome: a case series of 100 patients. $J$ Clin Psychopharmacol. 2012;32(4):548-550.

66. Murphy TK, Lewin AB, Storch EA, Stock S; American Academy of Child and Adolescent Psychiatry (AACAP) Committee on Quality Issues (CQI). Practice parameter for the assessment and treatment of children and adolescents with tic disorders. J Am Acad Child Adolesc Psychiatry. 2013;52(12):1341-1359.

\section{Publish your work in this journal}

Pediatric Health, Medicine and Therapeutics is an international, peerreviewed, open access journal publishing original research, reports, editorials, reviews and commentaries. All aspects of health maintenance, preventative measures and disease treatment interventions are addressed within the journal. Practitioners from all disciplines are invited to submit their work as well as healthcare researchers and patient support groups. The manuscript management system is completely online and includes a very quick and fair peer-review system. Visit http://www.dovepress.com/ testimonials.php to read real quotes from published authors. 